Erratum

\title{
Location of copper in larvae of Plectrocnemia conspersa (Curtis) (Trichoptera) exposed to elevated metal concentrations in a mine drainage stream
}

S. T. Darlington \& A. M. Gower

Department of Biological Sciences, Plymouth Polytechnic, Plymouth PL4 8AA, England

Hydrobiologia 196: 91-100, 1990.

On pages 95 and 98 of the above issue figures $2 \mathrm{~A} / 2 \mathrm{~B}$ and $4 \mathrm{~A} / 4 \mathrm{~B}$ were printed without the labelling referred to in the legends. We now present the corrected figures with their captions overleaf, and offer our apologies to the authors and readers for any inconvenience caused by this unfortunate error.

The Publishers 
(a)

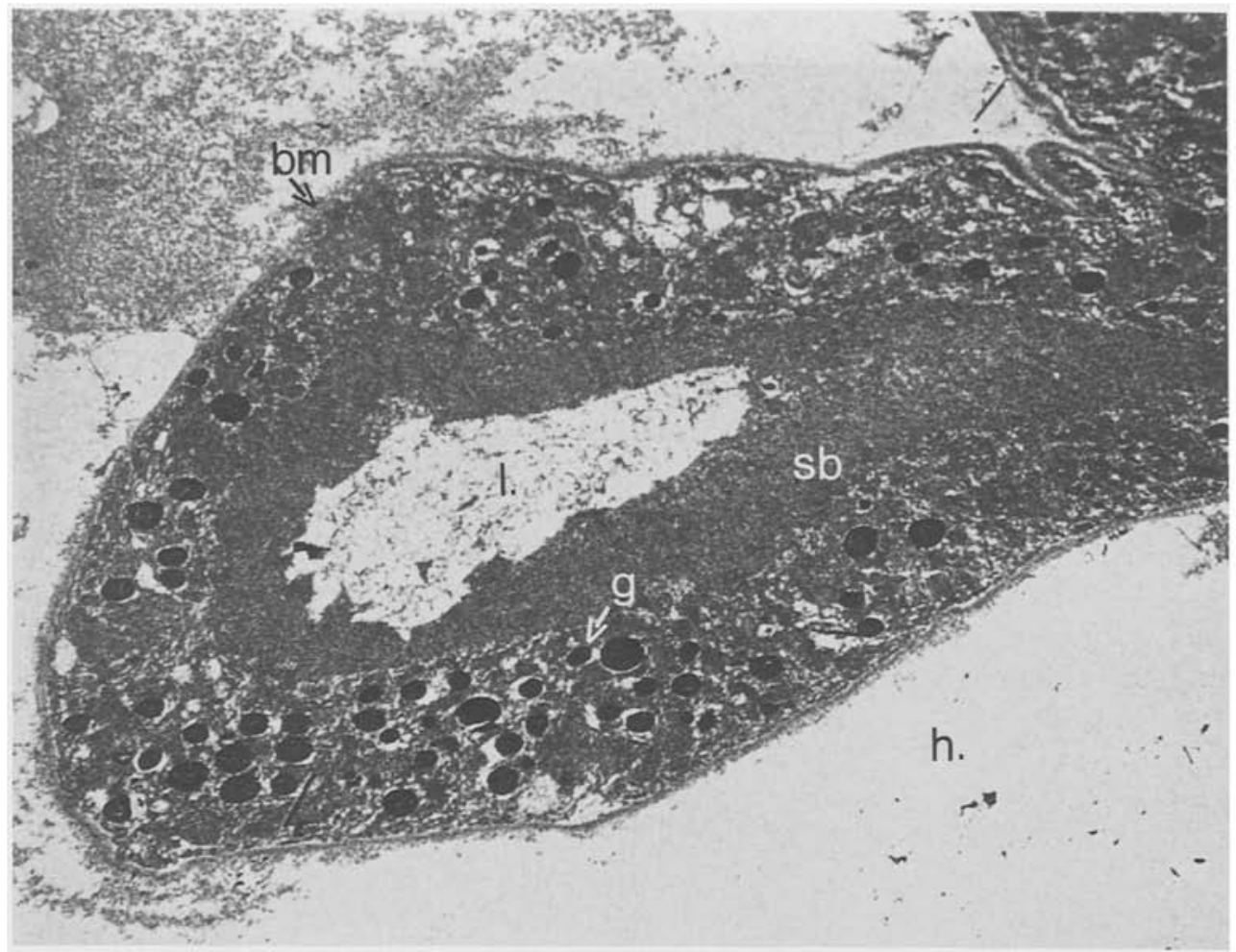

(b)

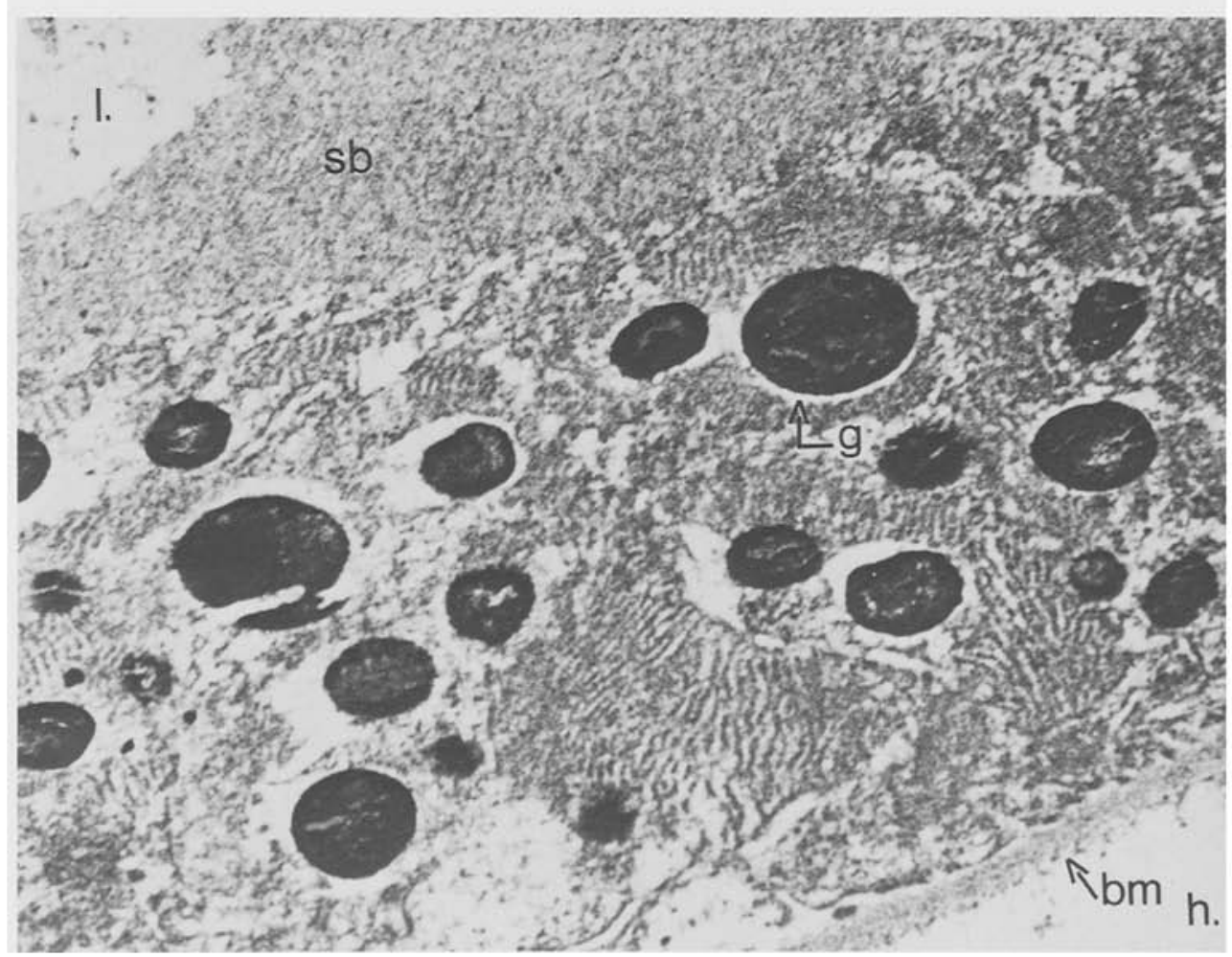

Fig. 2. Transmission electron micrographs of a section through a malpighian tubule of an instar III larva of $P$. conspersa from Site 1 in the Darley Brook. (a) $\times 9300$ and (b) $\times 32000$. bm, basement membrane; g, granule; $h$, haemocoel; 1 , lumen of tubule; $\mathrm{m}$, mitochondrion; sb, striated border. 
(a)

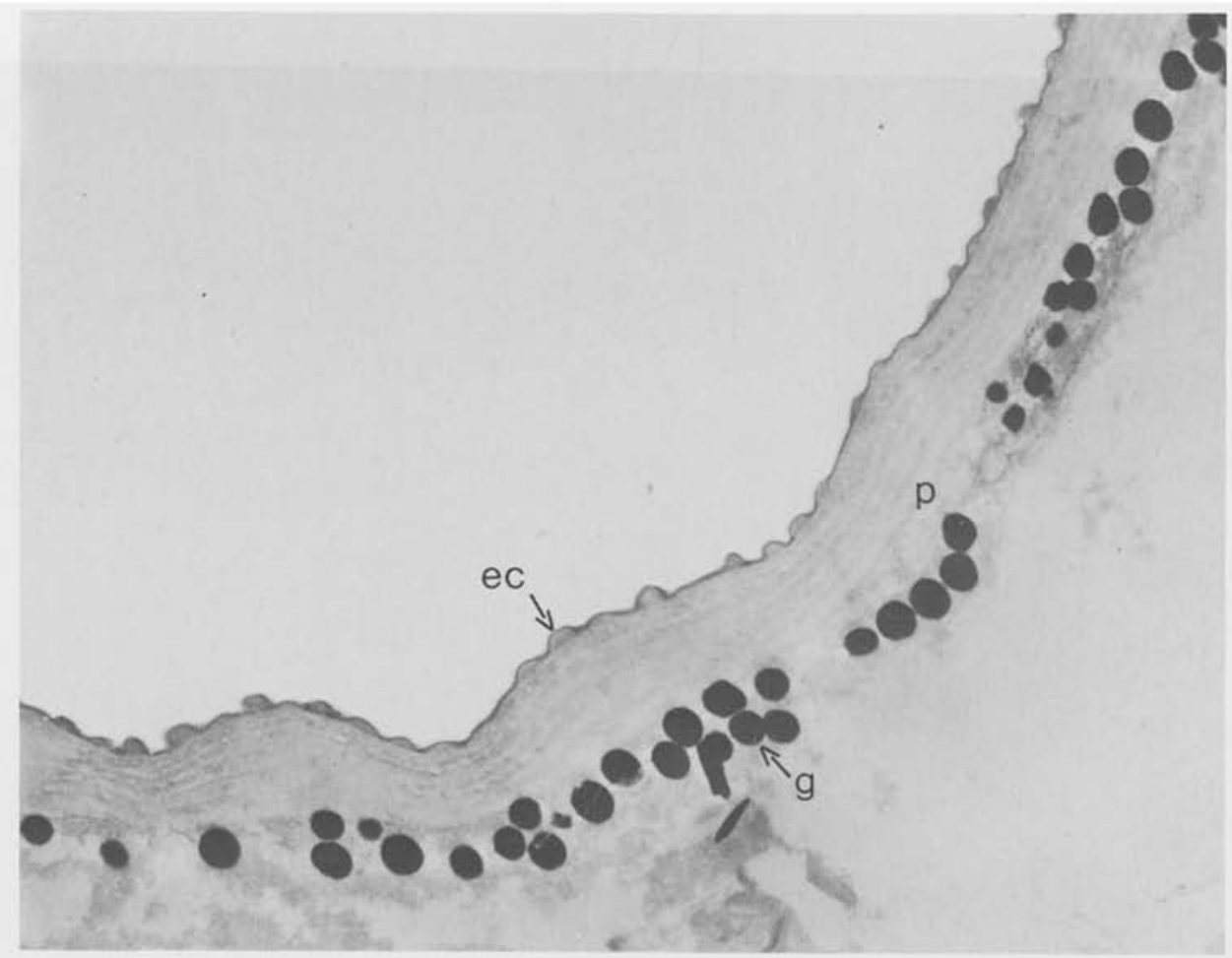

(b)

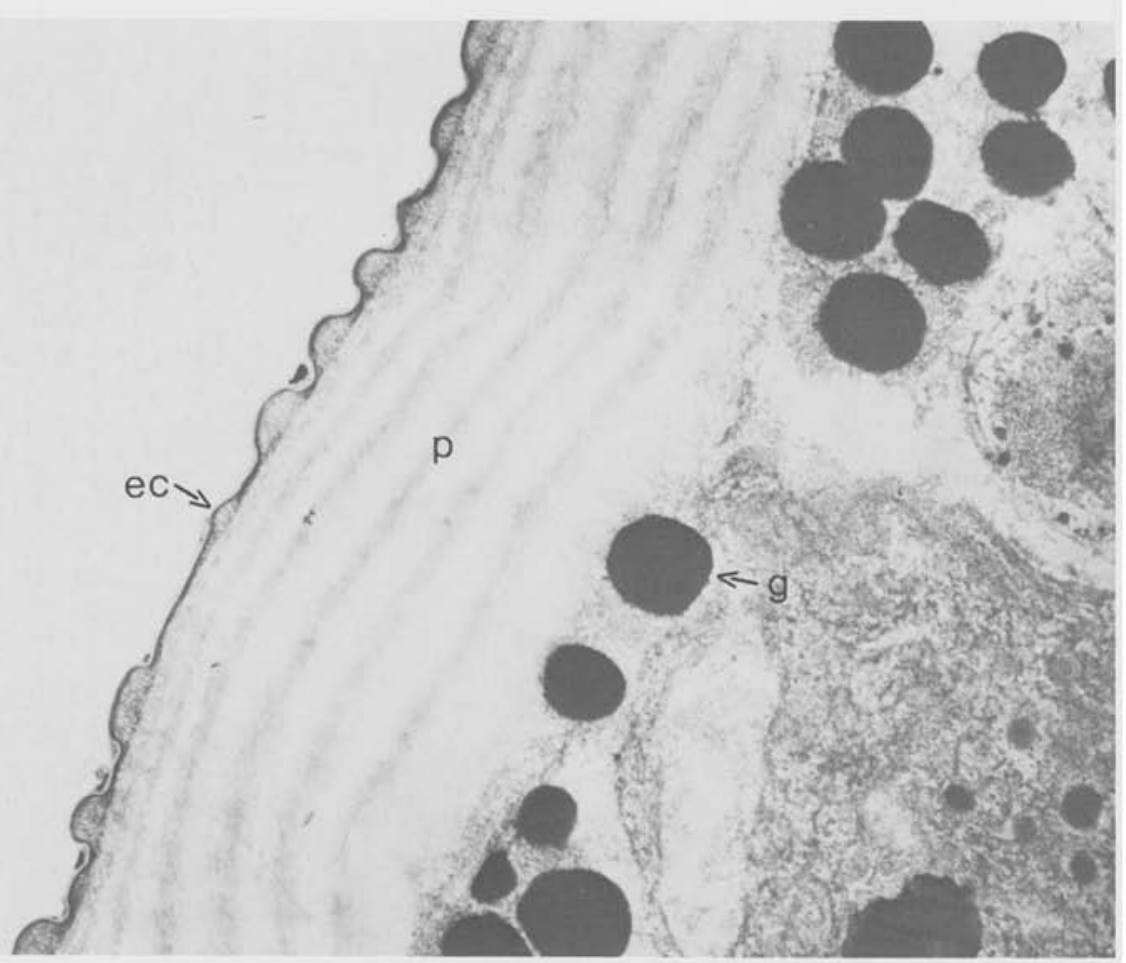

Fig. 4. Transmission electron micrographs of a section through the integument of an instar III larva of $P$. conspersa from Site 1 in the Darley Brook. (a) $\times 6600$ and (b) $\times 18300$. ec, epicuticle; g, granule; p, procuticle showing lamellar structure. 